CLINICAL STUDY

\title{
Triiodothyronine levels in relation to mortality from breast cancer and all causes: a population-based prospective cohort study
}

\author{
Ada Tosovic ${ }^{1}$, Anne-Greth Bondeson ${ }^{1}$, Lennart Bondeson ${ }^{2}$, Ulla-Britt Ericsson ${ }^{3}$ and Jonas Manjer ${ }^{1,4}$ \\ Departments of ${ }^{1}$ Surgery, ${ }^{2}$ Pathology, University and Regional Laboratories Region Skåne, ${ }^{3}$ Endocrinology and ${ }^{4}$ Plastic Surgery, Skåne University Hospital \\ Malmö, Lund University, SE-205 O2 Malmö, Sweden
}

(Correspondence should be addressed to A Tosovic; Email: ada.tosovic@med.lu.se)

\begin{abstract}
Objective: The potential association between thyroid hormones and breast cancer has been investigated in a large number of studies without conclusive results. This study investigated triiodothyronine $\left(\mathrm{T}_{3}\right)$ levels in relation to breast cancer mortality in a population with no breast cancer patients at baseline. An additional aim was to study $\mathrm{T}_{3}$ levels in relation to mortality from other cancers and all-cause mortality.

Design and methods: This was a population-based prospective cohort study including 2185 women in whom $\mathrm{T}_{3}$ levels were measured as part of a preventive health project, i.e. before diagnosis in women who later developed breast cancer. Mean follow-up was 24.1 years and record-linkage to The Swedish Cause-of-Death registry identified 471 women who died: 26 out of breast cancer and 182 from other cancers. Mortality was assessed using a Cox's analysis, yielding hazard ratios (HRs), with 95\% confidence intervals. Analyses of $\mathrm{T}_{3}$ as a continuous variable were repeated for pre- and peri/postmenopausal women separately.

Results: $\mathrm{T}_{3}$ levels were positively associated with the risk of breast cancer-specific death in the ageadjusted analysis: $\mathrm{HR}$ for $\mathrm{T}_{3}$ as a continuous variable was 2.80 (1.26-6.25). However, the crude analysis did not reach statistical significance. Breast cancer mortality was even higher in postmenopausal women: 3.73 (1.69-8.22), but stratified analyses included few events. There were no statistically significant associations between $\mathrm{T}_{3}$ levels and deaths from other cancers, age-adjusted HR: 1.09 (0.72-1.65) or all-cause mortality (1.25:0.97-1.60).

Conclusions: This study, the first of its kind on prospectively measured $\mathrm{T}_{3}$ levels, indicates that $\mathrm{T}_{3}$ levels are positively associated with breast cancer-specific mortality and that this is not related to a general effect on all-cause mortality.
\end{abstract}

European Journal of Endocrinology 168 483-490

\section{Introduction}

Thyroid disorders are common in women and an association with breast cancer would have a large impact. A large number of cross-sectional studies have investigated the association between breast cancer and thyroid disease, or levels of thyroid hormones, but these studies have been inconclusive $(1,2,3)$. Two recent prospective studies have, however, found a positive association between pre-diagnostic thyroid hormone levels and breast cancer risk $(4,5)$. These studies did not find any corresponding association between TSH and risk (ibid).

In spite of the potentially large clinical relevance, there are only two small studies, including 84 and 47 patients respectively, on thyroid hormones and clinical outcome, i.e. survival following breast cancer, but they found no clear associations $(6,7)$. A problem in studies measuring thyroid hormones in breast cancer patients is, however, that the disease per se, surgery, or adjuvant treatment may affect hormonal levels.

In order to investigate whether there is a clinically important association between thyroid hormone levels and breast cancer, the most relevant measurement is probably the breast cancer-specific mortality in a population with no breast cancer at baseline; this would reflect the net result of incidence and survival in a population. The only previous study on thyroid conditions and breast cancer mortality to our knowledge is Goldman et al. (8), but they found no association. They did, however, not include information on thyroid hormonal levels.

This study is a population-based, prospective cohort study including 2185 women with no breast cancer at baseline and in whom triiodothyronine $\left(\mathrm{T}_{3}\right)$ levels were measured as part of a preventive health project, 
i.e. before diagnosis in women who developed breast cancer. In a previous study based on this cohort, we have found a positive association between $\mathrm{T}_{3}$ levels and the risk of breast cancer (4), but it is not known whether this leads to a corresponding increase in breast cancer mortality.

The aim of this study was to investigate serum levels of $\mathrm{T}_{3}$ in relation to breast cancer mortality in a population with no breast cancer patients at baseline. An additional aim was to study $\mathrm{T}_{3}$ levels in relation to all-cause mortality.

\section{Materials and methods}

\section{The Malmö Preventive Project}

Originally, 10902 women participated in the Malmö Preventive Project. The project was established in 1974 when residents in Malmö, a city in southern Sweden, were invited to participate in a health survey. Entire birth cohorts, men and women, were examined until 1992 when the department closed. Approximately 70\% of invited subjects participated (9).

All women answered a questionnaire concerning sociodemographic information, lifestyle habits, and medical history. Questions on reproductive factors, e.g. menopausal status, were only included in women screened from April 1983 and onward. BMI $\left(\mathrm{kg} / \mathrm{m}^{2}\right)$ was assessed at baseline examination (9). A subject was considered to have a history of goiter if the question 'have you been treated for goiter' was answered with 'yes'. There was no available information on specific type of previous thyroid disorders or type of treatment. The study was approved by the ethics committee at Lund University: Dnr 652/2005 and Dnr 501/2006.

\section{$T_{3}$ analysis}

Blood samples were taken after an overnight fast with the patient in the supine position. The serum samples were analyzed for $\mathrm{T}_{3}$ and TSH in women born in 1928 and 1941 and examined in 1983 and 1984. In women born in 1935 (examined from 1990 to 1992), $\mathrm{T}_{3}$ was only measured in a subset of all women, i.e. those with pathological TSH values, a history of thyroid disease, or those with an enlarged thyroid gland at examination. In addition to this, the attending physician could also decide to analyze $\mathrm{T}_{3}(4)$. No analysis of thyroxin $\left(\mathrm{T}_{4}\right)$ had been performed at baseline in these women. $\mathrm{T}_{3}$ was measured by a double antibody RIA (reference interval 0.9-3.2 mmol/l) (10). Only six women had a value above the upper reference limit.

\section{Study cohort and follow-up on mortality}

Among 10902 women, reproductive data including menopausal status had been assessed in 8051 subjects.
$\mathrm{T}_{3}$ had been measured in 2383 women (1161 born in 1928, 907 born in 1941, and 315 born in 1935). Women with prevalent breast cancer $(n=35)$, goiter $(n=167)$, or both $(n=4)$ were identified and excluded from the study. Finally, the study population consisted of 2185 women with information on $\mathrm{T}_{3}$ and without breast cancer at baseline or a record of goiter. Information on vital status and cause of death was retrieved from the Swedish Cause-of-Death Registry up until 31 December 2010.

\section{Statistical analysis}

Quartile cut-points for $\mathrm{T}_{3}$ were based on the distribution among all women in the study population. $\mathrm{T}_{3}$ levels were investigated in relation to factors known to be associated with subsequent mortality, i.e. age at baseline, educational levels, alcohol consumption, and BMI. A Kendall's $\tau$-b test was used giving correlation coefficients $\left(\tau_{\mathrm{b}}\right)$ and corresponding $P$ values. Smoking was compared in relation to $\mathrm{T}_{3}$ quartiles using a $\chi^{2}$ test. A Bonferroni's correction was performed for $P$ values in pairwise $\chi^{2}$ comparisons multiplying the $P$ value with the number of comparisons. A two-sided $P$ value $<0.05$ was regarded as statistically significant. Missing categories were not included in these tests.

The primary endpoint was breast cancer as underlying cause of death. In addition to this, death from other cancers, death from other causes, and all causes were included in the main analysis. The distribution of the above mortality-related factors was examined in different groups defined by vital status and cause of death. These distributions were tested using the $\chi^{2}$ test as described earlier for smoking.

Each woman was followed from baseline until the end of follow-up, 31 December 2010, or until she died. Mean follow-up was 24.1 years (s.D. 5.3) and total follow-up included 52579 person-years. A Cox's proportional hazards analysis was used to estimate hazard ratios (HRs) with a confidence interval (CI) of $95 \%$ in relation to $\mathrm{T}_{3}$ levels. $\mathrm{T}_{3}$ levels were introduced as a continuous variable in the main analyses. $\mathrm{T}_{3}$ was not normally distributed $(P<0.001$ using a one sample Kolmogorov-Smirnov test), but to give estimates more readily interpretable, the original $\mathrm{T}_{3}$ values were used to obtain HRs. However, $\mathrm{T}_{3}$ values were also transformed using the natural logarithm in order to confirm whether the associations were statistically significant or not. Analyses were adjusted first for age at baseline and in a final model for all potential confounders. The limited number of breast cancer deaths did not allow inclusion of all covariates in the same model, but in relation to this endpoint, age and one additional factor at a time were included in the final model. In this way, a maximum of three variables were included in each model. In tables, only the model with the largest change from the crude $\mathrm{HR}$ for $\mathrm{T}_{3}$ was reported. The primary endpoint, breast cancer as cause of death, was also 
analyzed with $\mathrm{T}_{3}$ as a continuous variable stratified for menopausal status as we, in our previous study on $\mathrm{T}_{3}$ levels and breast cancer incidence, found that the association was considerably stronger in postmenopausal women compared with premenopausal. The stratified analyses did only allow the inclusion of one additional covariate, and we considered age at baseline to be most important. The stratified analyses were further evaluated by including a term for interaction in the model between $\mathrm{T}_{3}$ levels and menopausal status. A $P$ value $<0.05$ was considered as a statistically significant interaction. Finally, breast cancer death was analyzed in relation to different $\mathrm{T}_{3}$ quartiles where breast cancer-specific mortality was calculated per 10000 person-years. Corresponding HRs were calculated as earlier.

It is possible that subclinical disease may affect $\mathrm{T}_{3}$ levels, and in a sensitivity analysis, all analyses were repeated excluding all women who died before 2 years following baseline examination. SPSS version 18.0 (Lund, Sweden) was used for all analyses.

\section{Results}

Women in higher $\mathrm{T}_{3}$ quartiles were relatively old $\left(\tau_{\mathrm{b}}=0.29 ; \mathrm{P}<0.001\right)$, they had a lower educational level $\left(\tau_{\mathrm{b}}=-0.10 ; P<0.001\right)$, a lower alcohol consumption $\left(\tau_{\mathrm{b}}=-0.07 ; P<0.001\right)$, and they were more often overweight than women in lower $\mathrm{T}_{3}$ quartiles $\left(\tau_{\mathrm{b}}=0.17 ; P<0.001\right.$; Table 1$)$. There was no statistically significant association between $T_{3}$ levels and smoking (overall $P=0.82$ ).

Women who died from cancers other than breast cancer, or from causes other than cancer, were considerably older at baseline compared with women alive at the end of follow-up $(P<0.001$; Table 2). Women who died from causes other than cancer during follow-up had a lower educational level $(P=0.006)$, reported a lower alcohol consumption $(P=0.03)$, and had a higher BMI $(P<0.001)$ than women alive at the end of follow-up. Current smoking was more common among women who died from cancers other than breast cancer, and all causes other than cancer, compared with women alive at the end of follow-up $(P<0.001)$.

In this study, we observed a positive association between $\mathrm{T}_{3}$ levels and the risk of death from breast cancer (Table 3). The crude analysis did not reach statistical significance, but the risk increased following adjustment for age and other potential confounders. This association with mortality from breast cancer was only apparent among postmenopausal women compared with premenopausal. However, the terms for interaction between $\mathrm{T}_{3}$ levels and menopausal status did not reach statistical significance. All statistically significant results in the continuous analyses were

Table 1 Distribution of potential determinants for mortality according to serum $\mathrm{T}_{3}$ level. Column percent $P$ values are given in italics.

\begin{tabular}{|c|c|c|c|c|c|c|}
\hline \multirow[b]{2}{*}{ Factor } & \multicolumn{5}{|c|}{$\mathbf{T}_{3}$ quartile $\left(\mathrm{T}_{3}\right.$ range $\left.(\mathrm{mlU} / \mathrm{l})\right)$} & \multirow{2}{*}{$\begin{array}{c}\text { Kendall's } \boldsymbol{\tau} \text {-b } \\
\text { coefficient } \\
\left(\tau_{\mathrm{b}} ; P \text { values }\right)\end{array}$} \\
\hline & $\begin{array}{l}1(n=494 \\
(<1.50))\end{array}$ & $\begin{array}{c}2(n=704 \\
(1.60-1.80))\end{array}$ & $\begin{array}{c}3(n=456 \\
(1.90-2.00))\end{array}$ & $\begin{array}{c}4(n=531 \\
(2.10-4.30))\end{array}$ & $\begin{array}{l}\text { All }(n=2185 \\
(0.60-4.30))\end{array}$ & \\
\hline \multicolumn{7}{|l|}{ Age } \\
\hline$<50$ years & 62.1 & 46.6 & 26.1 & 21.5 & 39.7 & 0.29 \\
\hline$>50$ years & 37.9 & 53.4 & 73.9 & 78.5 & 60.3 & $(<0.001)$ \\
\hline \multicolumn{7}{|l|}{ Education } \\
\hline Missing & 4.5 & 4.1 & 4.2 & 3.2 & 4.0 & - \\
\hline$<12$ years & 53.0 & 53.6 & 62.5 & 64.2 & 57.9 & -0.10 \\
\hline 12 years & 20.9 & 27.4 & 22.1 & 21.8 & 23.5 & $(<0.001)$ \\
\hline$>12$ years & 21.7 & 14.9 & 11.2 & 10.7 & 14.5 & \\
\hline \multicolumn{7}{|l|}{ Smoking } \\
\hline Missing & - & - & 0.4 & 0.9 & 0.3 & - \\
\hline Never & 43.5 & 47.7 & 47.6 & 47.1 & 46.6 & $(0.82)^{a}$ \\
\hline Ex & 20.6 & 19.0 & 18.0 & 18.8 & 19.1 & \\
\hline$P$ value ${ }^{\mathrm{b}}$ & Ref. & 1.08 & 1.14 & 1.32 & - & \\
\hline \multicolumn{7}{|l|}{ Alcohol consumption } \\
\hline Missing & - & 0.1 & 0.4 & 1.5 & 0.5 & - \\
\hline Nothing & 14.2 & 14.1 & 13.2 & 19.0 & 15.1 & -0.07 \\
\hline Less than every week & 55.3 & 60.7 & 62.5 & 60.1 & 59.7 & $(<0.001)$ \\
\hline Every week & 30.6 & 25.1 & 23.9 & 19.4 & 24.7 & \\
\hline \multicolumn{7}{|l|}{$\mathrm{BMI}\left(\mathrm{kg} / \mathrm{m}^{2}\right)$} \\
\hline$<20$ & 14.8 & 10.1 & 7.9 & 7.5 & 10.1 & 0.17 \\
\hline$\geq 20-<25$ & 62.3 & 56.1 & 53.9 & 46.5 & 54.7 & $(<0.001)$ \\
\hline$\geq 25-<30$ & 17.0 & 26.1 & 27.9 & 30.5 & 25.5 & \\
\hline$\geq 30$ & 5.9 & 7.7 & 10.3 & 15.4 & 9.7 & \\
\hline
\end{tabular}

${ }^{\text {a } O v e r a l l ~} P$ value from the $\chi^{2}$ test. Not including missing values.

${ }^{b}$ Pairwise $\chi^{2}$ tests, with corrected $P$ values (multiplied with 3 ). Not including missing values. 
Table 2 Distribution of potential determinants for mortality according to vital status. Column percent $P$ values are given in italics.

\begin{tabular}{|c|c|c|c|c|c|c|}
\hline Factor & $\begin{array}{c}\text { Alive } \\
(n=1714)\end{array}$ & $\begin{array}{l}\text { Dead from } \\
\text { breast cancer } \\
(n=26)\end{array}$ & $\begin{array}{l}\text { Dead from } \\
\text { other cancers } \\
(n=182)\end{array}$ & $\begin{array}{l}\text { Dead from } \\
\text { other causes } \\
(n=263)\end{array}$ & $\begin{array}{l}\text { Dead from all } \\
\text { causes }(n=471)\end{array}$ & $\chi^{2}, P$ value $^{\mathrm{a}}$ \\
\hline \multicolumn{7}{|l|}{ Age } \\
\hline$<50$ years & 44.1 & 65.4 & 24.2 & 19.4 & 23.8 & $<0.001$ \\
\hline$>50$ years & 55.9 & 34.6 & 75.8 & 80.6 & 76.2 & \\
\hline$P$ value $^{\mathrm{b}}$ & Ref. & 0.09 & $<0.001$ & $<0.001$ & - & \\
\hline \multicolumn{7}{|l|}{ Education } \\
\hline Missing & 2.8 & 0.0 & 8.2 & 9.1 & 8.3 & - \\
\hline$<12$ years & 56.4 & 69.2 & 63.2 & 62.7 & 63.3 & 0.003 \\
\hline 12 years & 24.6 & 19.2 & 19.8 & 19.4 & 19.5 & \\
\hline$>12$ years & 16.2 & 11.5 & 8.8 & 8.7 & 8.9 & \\
\hline$P$ value ${ }^{\mathrm{b}}$ & Ref. & 1.53 & 0.39 & 0.006 & - & \\
\hline \multicolumn{7}{|l|}{ Smoking } \\
\hline Missing & 0.4 & 0.0 & 0.5 & - & 0.2 & - \\
\hline Never & 49.5 & 46.2 & 35.7 & 35.4 & 36.1 & $<0.001$ \\
\hline Current & 30.2 & 23.1 & 47.8 & 50.2 & 47.8 & \\
\hline Ex & 20.0 & 30.8 & 15.9 & 14.4 & 15.9 & \\
\hline$P$ value ${ }^{\mathrm{b}}$ & Ref. & 1.14 & $<0.001$ & $<0.001$ & - & \\
\hline \multicolumn{7}{|l|}{ Alcohol consumption } \\
\hline Missing & 0.6 & 0.0 & 0.5 & - & 0.2 & - \\
\hline Nothing & 14.2 & 26.9 & 12.6 & 21.3 & 18.3 & 0.04 \\
\hline Less than every week & 59.9 & 50.0 & 63.2 & 57.0 & 59.0 & \\
\hline Every week & 25.3 & 23.1 & 23.6 & 21.7 & 22.5 & \\
\hline$P$ value $\mathrm{b}^{\mathrm{b}}$ & Ref. & 0.57 & 2.01 & 0.03 & - & \\
\hline \multicolumn{7}{|l|}{ BMI $\left(\mathrm{kg} / \mathrm{m}^{2}\right)$} \\
\hline$<20$ & 9.9 & 7.7 & 9.3 & 11.8 & 10.6 & 0.004 \\
\hline$\geq 20-<25$ & 56.8 & 50.0 & 50.5 & 44.5 & 47.1 & \\
\hline$\geq 25-<30$ & 24.6 & 34.6 & 29.1 & 27.8 & 28.7 & \\
\hline$\geq 30$ & 8.6 & 7.7 & 11.0 & 16.0 & 13.6 & \\
\hline$P$ value ${ }^{\mathrm{b}}$ & Ref. & 2.13 & 0.93 & $<0.001$ & - & \\
\hline
\end{tabular}

${ }^{a}$ Overall $P$ value from the $\chi^{2}$ test tested for alive/dead from breast cancer/dead from other cancers/dead from other causes. Not including missing values.

${ }^{b}$ Pairwise $\chi^{2}$ tests, with corrected $P$ values (multiplied with 3 ). Not including missing values.

confirmed using the logarithmic $\mathrm{T}_{3}$ value (data not shown). In the quartile analysis, the risk of breast cancer death was higher in the fourth $\mathrm{T}_{3}$ quartile compared with the first quartile (Table 4). The limited number of events did not allow a quartile analysis stratified for menopausal status.
The risk of deaths from cancers other than breast cancer, causes other than breast cancer, and all causes were positively associated with $\mathrm{T}_{3}$ levels in the unadjusted analyses (Table 3). However, following adjustment for age, and subsequently for all potential confounders, these estimates were close to unity. When

Table 3 Mortality in relation to serum $T_{3}$ levels. The model with the largest influence on the HR, compared with the crude model, included alcohol consumption in addition to age at baseline; HR and corresponding $P$ values presented in table. All these multivariate models showed statistically significant $\mathrm{HRs}$ for $\mathrm{T}_{3}$.

\begin{tabular}{|c|c|c|c|c|c|c|c|c|}
\hline Cause of death & $\begin{array}{l}\text { Subjects in } \\
\text { analysis }(n)\end{array}$ & Dead $(n)$ & $\begin{array}{l}\text { HR }(95 \% \mathrm{Cl}) \\
\text { crude } \mathrm{T}_{3}\end{array}$ & $\begin{array}{c}P \text { value, } \\
\mathrm{T}_{3}\end{array}$ & $\begin{array}{c}\mathrm{HR}(95 \% \mathrm{Cl}) \text {, } \\
\text { age-adjusted } \\
\mathrm{T}_{3}\end{array}$ & $\begin{array}{c}P \text { value, } \\
\mathrm{T}_{3}\end{array}$ & $\begin{array}{l}\mathrm{HR}(95 \% \mathrm{Cl}) \\
\text { adjusted }^{\mathrm{a}} \mathrm{T}_{3}\end{array}$ & $P$, value $\mathrm{T}_{3}$ \\
\hline \multicolumn{9}{|l|}{ Breast cancer } \\
\hline All & 2185 & 26 & $2.22(0.92-5.37)$ & 0.077 & $2.80(1.26-6.25)$ & 0.012 & $2.82^{\mathrm{b}}(1.25-6.37)$ & $0.01^{\mathrm{b}}$ \\
\hline Premenopausal $^{\mathrm{C}}$ & 863 & 14 & $0.81(0.17-3.76)$ & 0.784 & $0.93(0.20-4.37)$ & 0.930 & - & - \\
\hline Postmenopausal $^{\mathrm{C}}$ & 1322 & 12 & $4.30^{\mathrm{d}}(1.88-9.86)$ & 0.001 & $3.73^{\mathrm{e}}(1.69-8.22)$ & 0.001 & - & - \\
\hline Other causes & 2185 & 445 & $1.60(1.26-2.02)$ & $<0.001$ & $1.17(0.90-1.52)$ & 0.237 & $1.07(0.82-1.41)$ & 0.610 \\
\hline All causes & 2185 & 471 & $1.63(1.30-2.05)$ & $<0.001$ & $1.25(0.97-1.60)$ & 0.087 & $1.16(0.89-1.50)$ & 0.280 \\
\hline
\end{tabular}

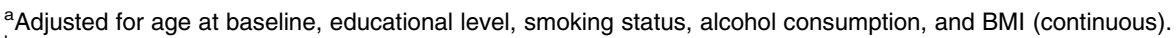

${ }^{\mathrm{b}}$ Adjusted for age at baseline and one factor at a time out of educational level, smoking status, alcohol consumption, and BMI (continuous).

${ }^{\mathrm{c}}$ Menopausal status at baseline.

dinteraction between $\mathrm{T}_{3}$ and menopausal status: $P$ value $=0.07$

e Interaction between $\mathrm{T}_{3}$ and menopausal status: $P$ value $=0.12$ 
Table 4 Breast cancer-specific mortality in relation to serum $\mathrm{T}_{3}$ levels. The model with the largest influence on the HR for the fourth quartile, compared with the crude model, included smoking status in addition to age at baseline; HR and corresponding $P$ value presented in table. All these multivariate models showed statistically significant $\mathrm{HRs}$ for the fourth $\mathrm{T}_{3}$ quartile, except for the model including age at baseline and $\mathrm{BMI}$ where this association was only borderline significant $(P=0.05002)$.

\begin{tabular}{|c|c|c|c|c|c|c|}
\hline $\mathbf{T}_{3}$ (quartile) & Subjects $(n)$ & $\begin{array}{c}\text { Dead from } \\
\text { breast cancer }(n)\end{array}$ & $\begin{array}{c}\text { Mortality/10 } 000 \\
\text { person-years }\end{array}$ & $\begin{array}{l}\mathrm{HR}(95 \% \mathrm{Cl}) \\
\text { crude } \mathrm{T}_{3}\end{array}$ & $\begin{array}{l}\mathrm{HR}(95 \% \mathrm{Cl}) \\
\text { age-adjusted } \mathrm{T}_{3}\end{array}$ & $\begin{array}{c}\mathrm{HR}^{\mathrm{a}}(95 \% \mathrm{Cl}) \text {, } \\
\text { adjusted } \mathrm{T}_{3}\end{array}$ \\
\hline 1 & 494 & 4 & 3.2 & 1.00 & 1.00 & 1.00 \\
\hline 2 & 704 & 10 & 5.8 & $1.82(0.57-5.81)$ & $2.07(0.65-6.63)$ & $2.07(0.65-6.61)$ \\
\hline 3 & 456 & 3 & 2.8 & $0.91(0.20-4.05)$ & $1.27(0.28-5.77)$ & $1.27(0.28-5.76)$ \\
\hline 4 & 531 & 9 & 7.4 & $2.48(0.76-8.09)$ & $3.61(1.08-12.1)$ & $3.65(1.09-12.2)$ \\
\hline Total & 2185 & 26 & 4.9 & - & - & - \\
\hline Overall $P$ value & - & - & - & 0.30 & 0.15 & 0.14 \\
\hline
\end{tabular}

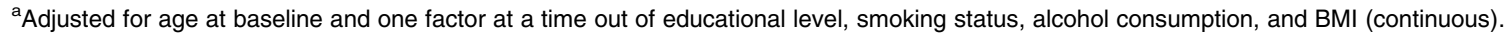

women who died within 2 years following baseline were excluded from the analyses, all results were similar (data not shown).

\section{Discussion}

This is the first prospective study on $\mathrm{T}_{3}$ levels in relation to breast cancer mortality. It shows that pre-diagnostic $\mathrm{T}_{3}$ levels are positively associated with the risk of breast cancer-specific death and that this is not related to a general effect on cancer death or all-cause mortality.

It may be asked whether breast cancer cases in this cohort are representative of the whole breast cancer population. This cohort mainly comprised middle-aged women and $70 \%$ of the women invited to the health examination attended (9). As we have no information about exposure to the studied risk factors in women outside this cohort, absolute risks may not be applicable to all age groups or to the general population. However, as there was a wide distribution of $\mathrm{T}_{3}$ levels, it was possible to make internal comparisons between subjects with relatively low and high values respectively. Hence, we consider that our estimates of relative risks were not considerably affected by selection bias.

Incomplete follow-up may affect the results. However, the Swedish Cause-of-Death Registry has been validated and found to have a completeness of about $97.3 \%$ in 2008 (11). Moreover, correctness of cause of death due to malignancies has been shown to be higher than $90 \%$ in the Swedish Cause-of-Death Registry (12).

Subjects with elevated $\mathrm{T}_{3}$ levels may already be within the health care system, possibly because of related symptoms, and due to this, the diagnosis of breast cancer might be established earlier than for euthyroid subjects. If true, this would lead to early diagnosis and an expected decrease in breast cancer mortality in this group. However, this is not likely as the contrary was found in this study. Furthermore, general mammography screening was introduced in Sweden in 1991 and stands for the majority of detection of breast cancer cases (13). It is also unlikely that thyroid status does affect participation in mammography screening. It should also be noted that most women with $\mathrm{T}_{3}$ levels in the fourth quartile in this study still had levels within the normal range, and these women probably did not have any symptoms of thyroid disease. It is not likely that the results in this study were due to a detection bias.

The method of analysis for $\mathrm{T}_{3}$ remained the same throughout the study period and all analyses were performed using a standardized collection of blood samples. $\mathrm{T}_{3}$ levels were analyzed following blood collection in 1983, 1984 and between 1990 and 1992. There are no recorded values for the coefficient of variance (CV) from the laboratory covering this period. However, reported within-laboratory $\mathrm{CV}$ at the time for $\mathrm{T}_{3}$ were in the order of $9-11 \%$ according to a large European analysis including 150 laboratories (14). Following this, we consider that $\mathrm{T}_{3}$ levels had a good reliability and that misclassification was probably low.

It is also important to consider true variation in $\mathrm{T}_{3}$ values as there is a well-known circadian and seasonal variation (15). Tracking of individuals, that is ranking of individuals over time, is, however, quite stable (16), and a true variation over time would most likely have led to an undifferential misclassification of $\mathrm{T}_{3}$ and, hence, attenuated risks.

The current study is the largest prospective study to date on thyroid hormone levels and breast cancer mortality, but the number of deaths due to breast cancer was still very limited. CIs were wide and the statistical power was relatively low. This led to an imprecision in the estimates related to $\mathrm{T}_{3}$ and breast cancer mortality. This was specifically apparent in the quartile analysis where $\mathrm{CI}$ was very wide, and the overall $P$ value did not reach statistical significance. Moreover, statistical power was an even more serious problem in analyses stratified for menopausal status, and these results, although statistically significant, should be regarded with caution.

An additional problem related to the limited number of breast cancer deaths was that not all confounders could be included at the same time in the final model for this endpoint. However, the models including age at baseline and one additional factor yielded statistically significant positive associations between $\mathrm{T}_{3}$ levels and 
breast cancer death; this indicates that these factors did not seriously confound the observed association.

Concerning death from cancers other than breast cancer, death from causes other than breast cancer, and all-cause mortality, there were a substantially larger number of events, and we consider that the lack of any strong associations was not merely the result of poor statistical power, i.e. a type II error.

In order to simplify the interpretation of HR obtained in the continuous analysis, we used original values even if they were not normally distributed. However, all statistically significant results in the continuous analyses were confirmed using the logarithmic $\mathrm{T}_{3}$ value. This is also what would be expected given the high correlation between raw and log-transformed $\mathrm{T}_{3}$ values.

The potential association between thyroid hormones and outcome following breast cancer has been discussed for more than a century. Several early studies used thyroid hormones/extracts as breast cancer treatment, but the effect was not apparent (2). We have found that no studies were published during the last 50 years on this topic. Goldman et al. (8), the only study on thyroid conditions and breast cancer mortality, found no excess risk of breast cancer death in women with thyroid disorders. Smyth et al. (17) followed 195 breast cancer patients and they found that positive TPO-Ab status was associated with a favorable survival, i.e. a lower risk of recurrent disease and death. Fiore et al. (6) examined 47 patients, among whom 16 died, and also found that positive thyroid antibody status (TPO-Ab and/or $\mathrm{Tg}-\mathrm{Ab}$ ) was associated with a low mortality, i.e. a good survival. These findings on recurrence-free survival and overall survival in relation to $\mathrm{TPO}-\mathrm{Ab}$ status were not confirmed by Jiskra et al. (7), including 84 patients where 11 died. Fiore et al. (6) and Jiskra et al. (7) also investigated $\mathrm{T}_{4}$ levels and TSH in relation to overall survival, but they found no clear associations. A problem in the interpretation of the above studies is that thyroid hormones, TSH and TPO-Ab, may indeed be affected by prevalent breast cancer, stress, or treatment. Generally, previous studies have been hampered by a low number of cases and short followup, and we have found no study on pre-diagnostic thyroid function and survival following breast cancer. Concerning mortality, no study has investigated thyroid function or $\mathrm{T}_{3}$ levels in relation to breast cancer-specific mortality in a 'breast cancer healthy' population.

All-cause mortality was associated with relatively high $\mathrm{T}_{3}$ levels in the crude analysis, but adjusted for age and other potential confounders, all estimates were close to unity. There are several recent meta-analyses and reviews on the potential association between thyroid conditions and all-cause mortality. Overt hyperthyroidism was associated with a slightly increased risk of all-cause mortality $(\mathrm{RR}=1.21: 1.05-1.38)$ in a metaanalysis by Brandt et al. (18), including more than 30000 patients. All the included studies were adjusted for age, but none for education, BMI, or alcohol consumption, and only some for smoking. Considering subclinical conditions, subclinical hyperthyroidism was positively associated with all-cause mortality in a metaanalysis of seven cohort studies (HR $=1.41: 1.12-1.79)$ using a general population as reference (19). Interestingly, another meta-analysis including ten prospective studies found no statistically significant association between subclinical hyperthyroidism and all-cause mortality (20). This study excluded subjects with goiter, and even in the highest quartile, most subjects were within the reference limits for $\mathrm{T}_{3}$. All in all, this makes it difficult to compare our results to studies based on overt thyroid conditions. Some of the previous studies also included patients treated with $\mathrm{T}_{4}$; that is, these studies may reflect an effect caused by exposure to exogenous hormones.

The biological mechanism explaining the association of $\mathrm{T}_{3}$ levels and breast cancer-specific mortality is not clear. However, the presence of thyroid hormone receptors in human breast and breast cancer cell lines has been established $(21,22,23,24)$, and the proliferative effect of $\mathrm{T}_{3}$ has been confirmed by various experimental studies on breast cancer. Our findings are in line with these data $(25,26,27,28)$.

It has been shown that $\mathrm{T}_{3}$ binds and stimulates the estrogen receptor, acting in synergy with estrogen on breast cancer cell lines, potentiating the estrogenic effect, and enhancing cell proliferation (29). The role of estrogen in carcinogenesis of the breast is well known and the possibility that this effect may be even stronger in conjunction with relatively high levels of $\mathrm{T}_{3}$ could in part explain the results in this study.

The positive association between $\mathrm{T}_{3}$ and breast cancer was specifically strong in postmenopausal women. Therefore, an imbalance between estrogen and $\mathrm{T}_{3}$ with an increased $\mathrm{T}_{3}$ /estradiol ratio may be more important than a pure synergistic effect between these two hormones for the risk of developing breast cancer. It has been suggested that this imbalance might enhance breast cancer development (25). This theory is in accordance with our findings that $\mathrm{T}_{3}$ levels in postmenopausal women are positively associated with breast cancer mortality. An important issue for future studies will be to evaluate the widespread, long-term use of $\mathrm{T}_{4}$ treatment in TSH-suppressive doses for benign thyroid disease $(30,31)$, and the management of women with subclinical hyperthyroidism $(32,33,34)$. Such studies will contribute with important evidence whether or not to treat mild and/or subclinical thyroid disorders.

\section{Conclusions}

In conclusion, the present prospective cohort study, the first of its kind on prospectively measured $\mathrm{T}_{3}$ levels, indicates that $\mathrm{T}_{3}$ levels are positively associated with breast cancer-specific mortality and that this is not related to a general effect on all-cause mortality. 


\section{Declaration of interest}

The authors declare that there is no conflict of interest that could be perceived as prejudicing the impartiality of the research reported.

\section{Funding}

This work was supported by The Swedish Cancer Society, The Ernhold Lundström Foundation, The Einar and Inga Nilsson Foundation, The Malmö University Hospital Cancer Research Fund, The Malmö University Hospital Funds and Donations, The Breast Cancer network at Lund University (BCLU), and The Region Skåne (ALF).

\section{References}

1 Sarlis NJ, Gourgiotis L, Pucino F \& Tolis GJ. Lack of association between Hashimoto thyroiditis and breast cancer: a quantitative research synthesis. Hormones $2002135-41$.

2 Goldman MB. Thyroid diseases and breast cancer. Epidemiologic Reviews 199012 16-28.

3 Smyth PP. The thyroid and breast cancer: a significant association? Annals of Medicine 199729 189-191. (doi:10.3109/0785 3899708999335)

4 Tosovic A, Bondeson AG, Bondeson L, Ericsson UB, Malm J \& Manjer J. Prospectively measured triiodothyronine levels are positively associated with breast cancer risk in postmenopausal women. Breast Cancer Research 201012 R33. (doi:10.1186/ bcr2587)

5 Tosovic A, Becker C, Bondeson AG, Bondeson L, Ericsson UB, Malm J \& Manjer J. Prospectively measured thyroid hormones and thyroid peroxidase antibodies in relation to breast cancer risk. International Journal of Cancer 2012.

6 Fiore E, Giustarini E, Mammoli C, Fragomeni F, Campani D, Muller I, Pinchera A \& Giani C. Favorable predictive value of thyroid autoimmunity in high aggressive breast cancer. Journal of Endocrinological Investigation 200730 734-738.

7 Jiskra J, Barkmanova J, Limanova Z, Lánská V, Smutek D, Potlukova E \& Antosova M. Thyroid autoimmunity occurs more frequently in women with breast cancer compared to women with colorectal cancer and controls but it has no impact on relapse-free and overall survival. Oncology Reports 200718 1603-1611.

8 Goldman MB, Monson RR \& Maloof F. Benign thyroid diseases and the risk of death from breast cancer. Oncology $1992 \mathbf{4 9}$ 461-466. (doi:10.1159/000227093)

9 Manjer J, Berglund G, Bondesson L, Garne JP, Janzon L \& Malina J. Breast cancer incidence in relation to smoking cessation. Breast Cancer Research and Treatment 200061 121-129. (doi:10.1023/ A:1006448611952)

10 Thorell JL \& Larson SM. Eds. Radioimmunoassay and related techniques. In Methodology and clinical applications, pp. 202-203. St luois: C M Mosby, 1978.

11 The National Board of Health and Welfare. Cause-of-Death history, methods and validity (in Swedish), www.socialstyrelsen. se/Publikationer2010/2010-4-33 (accessed 19 April 2012).

12 Johansson LA, Bjorkenstam C \& Westerling R. Unexplained differences between hospital and mortality data indicated mistakes in death certification: an investigation of 1,094 deaths in Sweden during 1995. Journal of Clinical Epidemiology 200962 1202-1209. (doi:10.1016/j.jclinepi.2009.01.010)

13 The National Board of Health and Welfare. Mammography questions and answers (in Swedish), http://www.sos.se/FULLTEXT/114/2002-114-5/2002-114-5.htm (accessed 17 December 2008).

14 Zucchelli GC, Pilo A, Chiesa MR \& Piro MA. Progress report on a national quality-control survey of triiodothyronine and thyroxin assay. Clinical Chemistry 198430 395-398.
15 Russell W, Harrison RF, Smith N, Darzy K, Shalet S, Weetman AP \& Ross RJ. Free triiodothyronine has a distinct circadian rhythm that is delayed but parallels thyrotropin levels. Journal of Clinical Endocrinology and Metabolism 200893 2300-2306. (doi:10.1210/jc.2007-2674)

16 Andersen S, Pedersen KM, Bruun NH \& Laurberg P. Narrow individual variations in serum $\mathrm{T}(4)$ and $\mathrm{T}(3)$ in normal subjects: a clue to the understanding of subclinical thyroid disease. Journal of Clinical Endocrinology and Metabolism 200287 1068-1072. (doi:10.1210/jc.87.3.1068)

17 Smyth PP, Shering SG, Kilbane MT, Murray MJ, McDermott EW, Smith DF \& O'Higgins NJ. Serum thyroid peroxidase autoantibodies, thyroid volume, and outcome in breast carcinoma. Journal of Clinical Endocrinology and Metabolism $1998 \mathbf{8 3}$ 2711-2716. (doi:10.1210/jc.83.8.2711)

18 Brandt F, Green A, Hegedüs L \& Brix TH. A critical review and meta-analysis of the association between overt hyperthyroidism and mortality. European Journal of Endocrinology $2011 \mathbf{1 6 5}$ 491-497. (doi:10.1530/EJE-11-0299)

19 Haentjens P, Van Meerhaeghe A, Poppe K \& Velkeniers B. Subclinical thyroid dysfunction and mortality: an estimate of relative and absolute excess all-cause mortality based on time-to-event data from cohort studies. European Journal of Endocrinology 2008159 329-341. (doi:10.1530/EJE-08-0110)

20 Ochs N, Auer R, Bauer DC, Nanchen D, Gussekloo J, Cornuz J \& Rodondi N. Meta-analysis: subclinical thyroid dysfunction and the risk for coronary heart disease and mortality. Annals of Internal Medicine 2008148 832-845.

21 Burke RE \& McGuire WL. Nuclear thyroid hormone receptors in a human breast cancer cell line. Cancer Research 197838 3769-3773.

22 Cerbon MA, Pichon MF \& Milgrom E. Thyroid hormone receptors in human breast cancer. Cancer Research 198141 4167-4173.

23 Lopez-Barahona M, Fialka I, Gonzalez-Sancho JM, Asuncion M, Gonzalez M, Iglesias T, Bernal J, Beug H \& Munoz A. Thyroid hormone regulates stromelysin expression, protease secretion and the morphogenetic potential of normal polarized mammary epithelial cells. EMBO Journal 199514 1145-1155.

24 Gonzales-Sancho JM, Figueroa A, Lopez-Barahona M, Lopez E, Beug $\mathrm{H}$ \& Munoz A. Inhibition of proliferation and expression of T1 and cyclin D1 genes by thyroid hormone in mammary epithelial cells. Molecular Carcinogenesis 200234 25-34. (doi:10.1002/mc.10046)

25 Saraiva PP, Figueiredo NB, Padovani CR, Bretani MM \& Nogueira CR. Profile of thyroid hormones in breast cancer patients. Brazilian Journal of Medical and Biological Research 200538 761-765. (doi:10.1590/S0100-879X200500050 0014)

26 Dinda S, Sanchez A \& Moudgil V. Estrogen-like effects of thyroid hormone on the regulation of tumor suppressor proteins, p53 and retinoblastoma, in breast cancer cells. Oncogene 200221 761-768. (doi:10.1038/sj.onc.1205136)

27 Conde I, Paniagua R, Zamora J, Blanquez MJ, Fraile B, Ruiz A \& Arenas MI. Influence of thyroid hormone receptors on breast cancer cell proliferation. Annals of Oncology 200617 60-64. (doi:10.1093/annonc/mdj040)

28 Nogueira CR \& Brentani MM. Triiodothyronine mimics the effects of estrogen in breast cancer cell lines. Journal of Steroid Biochemistry and Molecular Biology 199659 271-279. (doi:10. 1016/S0960-0760(96)00117-3)

29 Hall LC, Salazar EP, Kane SR \& Liu N. Effects of thyroid hormones on human breast cancer cell proliferation. Journal of Steroid Biochemistry and Molecular Biology 2008109 57-66. (doi:10.1016/j.jsbmb.2007.12.008)

30 Bonnema SJ, Bennedbaek FN, Ladenson PW \& Hegedüs L. Management of the nontoxic multinodular goiter: a North American Survey. Journal of Clinical Endocrinology and Metabolism 200287 112-117. (doi:10.1210/jc.87.1.112) 
31 Bonnema SJ, Bennedbaek FN, Wiersinga WM \& Hegedüs L. Management of the nontoxic multinodular goitre: a European Questionnaire Study. Clinical Endocrinology 200053 5-12. (doi:10.1046/j.1365-2265.2000.01060.x)

32 McDermott MT, Woodmansee WW, Haugen BR, Smart A \& Ridgway EC. The management of subclinical hyperthyroidism by thyroid specialists. Thyroid 200313 1133-1139. (doi:10.1089/ 10507250360731532)

33 Díez JJ. Hyperthyroidism in patients older than 55 years: an analysis of the etiology and management. Gerontology $2003 \mathbf{4 9}$ 316-323. (doi:10.1159/000071713)
34 Surks MI, Ortiz E, Daniels GH, Sawin CT, Col NF, Cobin RH, Franklyn JA, Hershman JM, Burman KD, Denke MA et al. Subclinical thyroid disease: scientific review and guidelines for diagnosis and management. Journal of the American Medical Association 2004291 228-238. (doi:10.1001/jama.291.2.228)

Received 29 June 2012

Revised version received 2 December 2012

Accepted 20 December 2012 